\title{
Elevators and staircase handrails as potential sources of nosocomial pathogens at Ndola Teaching Hospital, Zambia
}

\section{Tony Mulongo}

Ndola College of Biomedical Sciences, Ndola Zambia

\section{Kingsley Kamvuma}

Mulungushi University, School of Medicine and Health Sciences, Livingstone Zambia

Christopher N. Phiri

Mulungushi University, School of Medicine and Health Sciences, Livingstone Zambia

John A. Mulemena

Mulungushi University, School of Medicine and Health Sciences, Livingstone Zambia

Warren Chanda ( $\nabla$ chandawarren@yahoo.com )

Mulungushi University, School of Medicine and Health Sciences, Livingstone Zambia https://orcid.org/0000-0001-7305-979X

\section{Research Article}

Keywords: Elevators, Handrail, Ndola Teaching Hospital, Microbial colonization, inanimate objects

Posted Date: November 10th, 2021

DOI: https://doi.org/10.21203/rs.3.rs-1066554/v1

License: (c) (1) This work is licensed under a Creative Commons Attribution 4.0 International License. Read Full License 


\section{Abstract}

This study aimed to assess microbial colonization of elevators and the staircase handrail at Ndola Teaching Hospital. Swabs from elevators and staircase handrail were cultured on Blood, MacConkey and Mannitol Salt agar for $24-48 \mathrm{~h}$ at $35-37^{\circ} \mathrm{C}$. All observed bacterial colonies were sub-cultured for identification. Data analysis was conducted with Microsoft excel 2010 and SPSS version 20 statistical software. A 2-tailed Pearson Correlation test was used to assess for significant differences in colonization prevalence between the two elevators and handrail. A total of 94 bacteria species were isolated, among which $75(78.8 \%)$ were isolated from elevators while $19(20.2 \%)$ were isolated from the staircase handrail. Most bacteria were isolated from exterior buttons followed by doors and interior of elevators whereas the basement, ground and sixth floor sections of the staircase handrail were largely contaminated with S. aureus, non-spore-forming Gram-positive bacilli, Klebsiella spp, coagulase-negative Staphylococci and Enterobacter spp. Overall, the commonest isolated bacteria were S. aureus (33\%) followed by non-spore-forming Gram-positive bacilli (16\%), coagulase-negative Staphylococci, and endospore-forming Gram-positive bacilli (13.8\% apiece), Streptococci (7.4\%), and Klebsiella species (6.4\%). A strong relationship existed between the prevalence of bacteria colonizers of elevators and the staircase handrail $(p<0.01)$. Therefore, the study showed that elevators and the staircase handrail possess viable microorganisms and may act as potential sources of nosocomial infections especially to immunocompromised patients in hospitals, and this calls for proper and effective infection control and prevention strategies to lessen microbial population from dry surfaces.

\section{Introduction}

The human community is surrounded by an environment that harbors a wide range of both pathogenic and non-pathogenic microorganisms. The hospital is no exception, if anything, it may harbor more pathogenic than non-pathogenic when infection control programs are not strengthened. Thanks to our bodies' immune system that controls and regulates the proliferation of these microbes. However, the hospital houses both immunocompetent and immunocompromised individuals; and the latter are prone to contracting nosocomial and opportunistic infections (1). In addition, microorganisms in hospital environments may be contracted from both wet and dry inanimate surfaces (2). For this reason, it is important to set up deliberate policies on microbial monitoring of the inanimate environment to detect the presence of specific nosocomial pathogens which can be used to evaluate the efficacy of routine cleaning and disinfection practices (3).

Hospital-acquired infections pose a great challenge to the welfare of patient management. This ultimately increases the length of stay for inpatients and further has a huge impact on hospital costs. Nosocomial infections usually affect immunocompromised patients due to age, underlying diseases, medical or surgical treatments and, antimicrobial use and long-term care in hospitals contribute to the emergence of nosocomial pathogens (4). There is up to $70 \%$ chance for patients admitted to a room previously occupied by a patient with Clostridium difficile, Pseudomonas aeruginosa, methicillin-resistant Staphylococcus aureus (MRSA), Acinetobacter baumannii, or vancomycin-resistant enterococci (VRE) to 
obtain these microbes during hospital stay $(3,5,6)$. Thus, microbial hygiene examinations may provide insights into how clean a surface is. During nosocomial outbreaks, various surfaces such as taps, sinks, toilets, beds, and floors are sampled for epidemiological investigations to assess the spread of nosocomial pathogens (7).

To mitigate these challenges, enhancing hospital surveillance programs for nosocomial pathogens is of utmost importance. Moreover, having a formidable infection control team that incorporates four key infection control components such as an effective hospital epidemiologist, one infection control practitioner, active surveillance mechanisms, and ongoing control efforts, have proven to reduce the rate of nosocomial infection $(4,8)$.

However, the survival of microorganisms on surfaces is dependent on factors such as temperature and moisture. For instance, it was observed that Gram-negative bacteria persist longer on surfaces than Gram-positive bacteria and, their survival was further enhanced with humidity (2). In the same systemic review study, it was revealed that bacteria such as Enterococcus (including Vancomycin-Resistant Enterococci), Staphylococcus aureus (including Methicillin-Resistant Staphylococcus aureus), Streptococcus pyogenes, Escherichia coli, Acinebacter spp., Klebsiella spp., Pseudomonas aeruginosa, Serratia marcescens, and Shigella spp., survived for months on dry surfaces while Bordetella pertussis, Haemophilus influenza, Proteus vulgaris, and Vibrio cholerae survived only for few days. Despite various cleaning and disinfection practices that are performed in hospitals, complete elimination of bacterial colonization does not occur as MRSA and Acinetobacter baumannii have been detected on environmental surfaces after cleaning and disinfection of a hospital ward (9). Thus, hospital environment surfaces should regularly be monitored for the presence of nosocomial pathogens. So, dry surfaces like hospital staircase rails and elevators that are frequently utilized may be potential reservoirs of bacteria and may act as conduits for hospital-acquired infections.

Ndola Teaching hospital (NTH) has two functional elevators; one runs from the ground floor to the third floor while the other runs from basement level to the seventh floor. Besides the hospital having two functional elevators, and/or when these elevators are down (non-functional), the staircases that run from the basement level to the rooftop are an option. Moreover, the hospital elevators and staircases become busier during patient visiting hours. Since staircases and elevators are used by hospital staff, patients and visitors, and are a vehicle for transporting foods, hospital waste, biological specimens for laboratory examination, and corpses to the mortuary; we hypothesized that the cleaning in these areas may not be effective to reduce bacterial presence, and hence may act as sources of hospital-acquired infections and conduits of infection transmission. Also, it has been suggested that hospital surfaces with hand contact are contaminated with nosocomial pathogens and may act as vectors for cross-contamination, posing a risk of pathogen transmission from inanimate surfaces to susceptible patients (2). Therefore, this study aimed at assessing microbial colonization of elevators and the staircase handrail at NTH.

\section{Materials And Methods}




\section{Study site and study design}

This study was a prospective cross-section laboratory-based study that focused on understanding the bacterial colonization of elevators and the staircase handrail at Ndola Teaching Hospital. The hospital is the second-largest health institution in Zambia with a capacity of 851 beds and 97 baby cots. It is also a referral center for Copperbelt, Luapula, and North-western provinces of Zambia and serves a population of 503649 of Ndola district. The hospital, at the time of the study, had two functional elevators; one elevator runs from the ground floor to the third floor and was designated as elevator 1 and the other one that runs from the basement to the seventh floor was designated as elevator 2. Besides the two elevators, there is a staircase handrail that runs from the basement to the seventh floor.

\section{Sample collection, culture, and inclusion criteria}

The presence/absence of microorganisms on the dry steel surface of the elevator and staircase handrail was assessed using the pre-moistened swabbing method to increase the chances of isolating microorganisms as reviewed by Galvin et al (2012) (3). Sterile cotton wool swabs were used to collect the specimens. Swabs pre-moistened in normal saline were used to scrub the interior buttons, exterior buttons, door walls, and interior flat handrails and interior walls of both elevators. The staircase handrail was also swabbed with pre-moistened swabs. These swabs were then put back in the transport media tube and were immediately transported to the microbiology laboratory within 20 minutes. Swabs were labeled with swabbing site, date, and time of collection. However, samples without proper labeling and those exceeding $2 \mathrm{~h}$ without being cultured were excluded from the study. Also, all specimens with suspicion of cross-contamination were excluded from the study. To avoid cross contaminations, one specimen per time was processed in the Biosafety cabinet.

Upon arrival to the microbiology laboratory, each swab was inoculated on Blood Agar (BA; Himedia, India), Mannitol Salt Agar (MSA; Sigma, USA), and MacConkey Agar (MA; Himedia, India), and the plates were incubated for 24 hours at 35 - 37खC. The plates were then checked for growth and all different colonies growing on any of the media were then subcultured on a new set of plates to obtain pure colonies for definitive identification. If no growth appeared, the same plates were further incubated for 24 more hours and dealt with in the same manner.

Microbial processing and identification.

After $24 \mathrm{~h}$ to $48 \mathrm{~h}$ of microbial growth, a Gram stain was used to differentiate Gram-positive bacteria from Gram-negative bacterial cells. After Gram staining, Gram-positive organisms were identified by assessing the catalase and coagulase production. Further identification of Coagulase-negative Staphylococci (CNS) with novobiocin susceptibility testing was performed to rule out Staphylococcus saprophiticus (novobiocin resistant). In this testing, a pure colony suspension equivalent to a McFarland 0.5 opacity standard of an 18-24h culture was prepared and inoculated on Mueller-Hinton Agar (10) and novobiocin (5ug) disk aseptically placed onto the inoculated agar surface. The plate was then incubated for 18-24 hours at 35-37هC. The diameter of the zone of inhibition around the novobiocin disk was measured (in 
millimeters) and the zone size $<16 \mathrm{~mm}$ was considered resistance whereas the zone size greater or equal to $16 \mathrm{~mm}$ was regarded as sensitive.

For the Gram-negative organisms, besides using catalase and oxidase testing, the strains were exposed to different identification tests using in-house and/or commercially prepared biochemical media such as Sulphur Indole Motility (SIM) agar (Becton, Dickinson and company [BD], USA), Triple Sugar Iron (TSI) agar (BD, USA), Lysine Iron Agar (BD, USA), Citrate agar (Mast Group Ltd, UK), urea media (BD, USA), oxidase reagent (Himedia, India), hydrogen sulfide (VYKing Pharmaceuticals Ltd, Zambia). Quality control was performed with Staphylococcus aureus (ATCC 25923), Escherichia coli (ATCC 25922) standard strains.

\section{Data processing and analysis}

Data entry was done and managed in Microsoft excel 2010 and statistical analyses were performed by using SPSS version 20 statistical software. A 2-tailed Pearson Correlation test was used to assess for significant differences in colonization prevalence between the two elevators and the handrail.

\section{Results}

A total of 94 bacterial isolates were obtained from culture swabs of both elevators and the handrail. Out of 94 isolates, $28.7 \%$ (27) bacteria were isolated from elevator $1,51.1 \%$ (48) from elevator 2, and $20.2 \%$ (19) from the staircase handrail (Table 1). 
Table 1

The distribution of bacteria isolates from Staircase Handrail and Elevators

\begin{tabular}{|lllll|}
\hline Bacterial isolate & $\begin{array}{l}\text { Elevator } \mathbf{1} \\
\%(\mathbf{n})\end{array}$ & $\begin{array}{l}\text { Elevator } \mathbf{2} \\
\%(\mathbf{n})\end{array}$ & $\begin{array}{l}\text { Handrail } \\
\%(\mathbf{n})\end{array}$ & $\begin{array}{l}\text { Total } \\
\%(\mathbf{n})\end{array}$ \\
\hline S. aureus & $19.4(6)$ & $51.6(16)$ & $29.0(9)$ & $33.0(31)$ \\
\hline Endospore forming GPR & $38.5(5)$ & $61.5(8)$ & 0 & $13.8(13)$ \\
\hline CNS & $23.1(3)$ & $53.8(7)$ & $23.1(3)$ & $13.8(13)$ \\
\hline S. saprophyticus & $66.7(2)$ & $33.3(1)$ & 0 & $3.2(3)$ \\
\hline Non spore forming GPR & $46.7(7)$ & $26.7(4)$ & $26.7(4)$ & $16.0(15)$ \\
\hline Streptococcus spp & $28.6(2)$ & $57.1(4)$ & $14.3(1)$ & $7.4(7)$ \\
\hline Klebsiella spp & $16.7(1)$ & $66.7(4)$ & $16.7(1)$ & $6.4(6)$ \\
\hline E. coli & $33.3(1)$ & $66.7(2)$ & 0 & $3.2(3)$ \\
\hline Enterobacter spp & 0 & $50(1)$ & $50(1)$ & $2.1(2)$ \\
\hline Providencia rettgeri & 0 & $100(1)$ & 0 & $1.1(1)$ \\
\hline Total & $\mathbf{2 8 . 7 ( 2 7 )}$ & $\mathbf{5 1 . 1}(\mathbf{4 8 )}$ & $\mathbf{2 0 . 2}(\mathbf{1 9})$ & $100(94)$ \\
\hline \%: percentage, n: number, GPR: Gram-positive rods, spp: species, CNS: coagulase-negative \\
\hline
\end{tabular}

Staphylococci

Elevator 2 (E2) was highly contaminated followed by elevator 1(E1) then the staircase handrail (SHR). This was partly because the E2 runs from the basement to the seventh floor of the hospital building and people opt to use it more often as compared to E1 which only moves from the ground floor to the third floor; however the staircases are infrequently used as shown by less number of microbial isolates from the SHR. Among the bacterial isolates, Staphylococcus aureus (S. aureus) was more prevalent on SHR (47\%) followed by E2 (33\%) and E1 (22\%); endospore-forming Gram-positive rods (EGPR) were more from SHR $(21 \%)$ followed by E1 and E2 with $19 \%$ and 17\%, respectively (Fig. 1A). Furthermore, coagulasenegative Staphylococci (CNS) were mostly isolated from SHR (16\%) followed by E2 (15\%) then E1 (11\%) whereas Streptococci were more from E2 (8\%) followed by E1 (7\%) then SHR (5\%); but Staphylococcus saprophyticus (S. saprophyticus) and non-spore-forming Gram-positive rods (NGPR) were only isolated from the elevators (fig. 1A).

Overall, figure 1B (and Table 1) further revealed that the commonest colonizer amongst all isolated bacteria was $S$. aureus (33\%) followed by NGPR (16\%), CNS \& EGPR (13.8\% apiece), Streptococci (7.4\%), and Klebsiella spp (6.4\%). Yet, the commonest isolates from individual equipment were NGPR $(26 \% ; 7)$ followed by S. aureus $(22 \% ; 6)$, S. aureus $(33 \% ; 16)$ followed by EGPR $(17 \% ; 8)$, and S. aureus $(47 \% ; 9)$ followed by NGPR $(21 \% ; 4)$ for E1, E2, and SHR respectively (Table 1$)$. Since elevators are widely used as shown by the highest number of isolates (Table 1), we hypothesized that elevator buttons (both interior 
and exterior) and interior doors, walls, and rails could be heavily contaminated as they are frequently touched by people using elevators, and we wanted to identify the commonest contaminants. On average, $S$. aureus was identified as the commonest colonizer of exterior buttons, door walls, and interior handrail and walls of elevators followed by EGPR colonizing mostly the interior handrail and walls, door walls, and interior buttons (Fig. 2).

However, NGPR was only isolated from the exterior and interior buttons (Fig. 2). Previous studies have revealed an insignificant difference in the transfer rates of Gram-positive and Gram-negative bacteria from inanimate surfaces to fingertips (11). Our study isolated the highest percentage of Gram-positive bacteria (86\%) and less of Gram-negative bacteria (14\%) as shown in Fig. 3. We further discovered that the basement, ground floor, and sixth floors were the most contaminated sections of the Staircase handrail, and were frequently colonized with $S$. aureus and NGPR with the addition of Klebsiella spp (basement), CNS (ground floor), and Enterobacter spp (6th floor)(data not shown). Finally, we sought to understand the significant differences in colonization prevalence between E1 and E2, E1 and SHR, and E2 and SHR with a 2-tailed Pearson correlation test. We found that there was a strong correlation between E1 and E2 [r(25) $=0.90, p<0.01], E 1$ and SHR $[r(17)=0.93, p<0.01]$, and E2 and SHR $[r(17)=0.74, p<0.01]$. These suggested that there was a statically strong relationship with the type of bacterial colonizers that were isolated from the elevators and staircase handrail.

\section{Discussion}

Elevators and the staircase handrail are very useful in facilitating people's movements and support within a multi-storey building. Hospitals are an example of such buildings that utilize elevators for easy and fast movements of doctors, nurses, patients, visitors, foods etcetera, from one floor to the other. Due to their usage by multiple people, elevators, especially elevator buttons in the hospital may be an additional or neglected source of microbial contamination (12). On the other hand, staircase railing provides stability for people especially young children, the elderly, people with disabilities, and fatigued patients, and others that may graze the railing lightly with their hands in case they need extra support or balance as they ascend or descend the staircases. Due to this purpose, handrails are usually colonized with both viable and nonviable pathogenic microorganisms in hospitals (13). All these microbial colonizers can be minimized with proper disinfection and cleaning practices. Hospital cleaning and disinfection is also the hallmark of infection control. A plethora of evidence indicates that contamination of hospital surfaces plays an important role in the transmission of several key healthcare-associated pathogens $(14,15)$. Therefore, we thought to understand the effectiveness of cleaning and disinfection practices at Ndola Teaching Hospital (NTH) via assessment of bacterial colonization of elevator buttons, walls and rails, and the staircase handrail.

The results of the current study reveal that solid surfaces are colonized by viable organisms and people using them can act as carriers. These findings are in agreement with the results obtained in previous studies $(16,17)$ where they isolated pathogenic bacteria from elevator buttons and concluded that elevators are contaminated with potential pathogens. Al-Ghamdi et al (2011) reported the highest 
contamination rate of elevator buttons (97\%) and our study confirms that elevator buttons are heavily contaminated with the rate of less than $40 \%$ (Fig. 1). The difference could be attributed to the less number of elevators that were included in our study while Al-Ghamdi et al. included residential and shopping mall elevators. Furthermore, our study showed that besides elevator buttons, interior walls and handrails were contaminated mostly by $S$. aureus and endospore-forming Gram-positive bacilli (Fig. 2). These findings could be as a result of touching or leaning on the elevator walls and holding the interior handrail for support. According to previous studies, there is no significant difference in the rate of spreading Gram-positive and Gram-negative bacteria between inanimate surfaces and animate ones (11, 18), but our study found the highest percentage of Gram-positive bacteria (86\%) and less of Gramnegative bacteria (14\%) as shown in figure 3 . The survival of bacteria on inanimate objects is largely enhanced by the relative humidity (18). A study by Tang (2009) found the high prevalence of Grampositive cocci followed by Gram-positive rods, Gram-negative rods, and Gram-negative cocci in indoor air (19), and $S$. aureus can persist longer at low humidity (20) which could explain the highest prevalence of S. aureus in our study (Fig. 1B). Thus, Gram-positive organisms tend to tolerate dry conditions better than Gram-negative organisms due to variations in the bacterial cell wall structure, because the lipid doublelayer structure with a thin peptidoglycan layer of Gram-negative bacteria does not adequately confer protection against physical stress, hence humidity is required to enhance their survival on inanimate surfaces (18).

The Gram-positive bacteria such as S. aureus, EGPR, CNS, S. saprophyticus, NGPR, and Streptococcus spp were the most isolated microorganisms from both elevators while Gram-negative ones included Escherichia coli, Klebsiella spp, Enterobacterspp, and Providencia rettgei. Despite S. aureus being part of the normal human microbiota, it may cause a wide range of infections such as bacteremia, sepsis, pneumonia, endocarditis, and osteomyelitis, and can cause hard to treat nosocomial infection due to multidrug resistance acquisition $(21,22)$. The second most prevalent bacteria in our study was the endospore-forming Gram-positive rods (EGPR, Fig. 1B). These organisms are widely distributed in the environment and can also be found in dust and maybe medically insignificant but may cause selflimiting infections. The other type of isolates were the non-endospore forming Gram-positive rods (NGPR) and CNS that are human commensals and may also be present in the inanimate hospital environment and can cause nosocomial infection $(23,24)$. Further Gram-positive bacteria isolated with less frequency but may cause nosocomial infection such as sinusitis, otitis media, pneumonia, bacterial meningitis, bacteremia, and acute exacerbations of chronic bronchitis, were Streptococcus spp and S. saprophyticus (Fig. 1B). Among the Gram-negative bacteria isolated in this study, Klebsiella spp were the most prevalent, and this finding agreed with Nawas et al (2018) who isolated the same bacteria from $17 \%$ of the sampled elevators (25). Within the Klebsiella spp, there is K. pneumoniae, one of the common causes of hospitalacquired pneumonia, urinary tract infections, and intraabdominal infections (26), but our study did not determine whether K. pneumoniae was amidst the isolated Klebsiella spp.

On the other hand, the staircase handrail (SHR) was also assessed for bacterial colonization since it provides stability for people as they ascend or descend the staircases. As expected, SHR was also contaminated but few isolates in comparison with those from elevators were noted. Amongst these 
isolates, S. aureus (47\%) topped the list followed by NGPR (21\%), CNS (15\%), and < $1 \%$ apiece of Klebsiella spp, Streptococcus spp, and Enterobacter spp, and our findings were in agreement studies conducted elsewhere $(2,18,27,28)$. We further discovered that the basement, ground, and sixth floors were the most contaminated sections of the SHR, and were frequently colonized with $S$. aureus and NGPR with the addition of Klebsiella spp (basement), CNS (ground floor) and Enterobacterspp (6th floor). This maybe because these areas are frequently populated by people awaiting to use the elevators as they receive people from outside the hospital (i.e. basement and ground floors) while the sixth floor could be due to the presence of a fee paying clinic, restaurant and is also hosting a research centre - so maybe frequently visited thereby contaminating the SHR. The study further found a strong correlation between the prevalence of bacteria colonizers of elevators and the staircase handrail $(p<0.01)$.

In conclusion, our study has revealed that elevators and the staircase handrail are contaminated with both Gram-positive and negative bacteria and are equally important areas that require a keen interest in infection prevention and control, as they may be a conduit for hospital-acquired nosocomial infections. Thus, when hospital wards, beds, sinks, etc are being swabbed periodically to assess the contamination levels during infection control programs, elevators and the staircase handrail should not be overlooked or neglected. The study further revealed that some isolates such as $S$. aureus, Escherichia coli, and Klebsiella species are common carriers of antibiotic-resistant genes, and it would have been more informative if the susceptibility pattern was assessed or resistant markers were identified, however, our study could not, hence additional studies are warranted. Further limitations of this study included the lack of speciating most of the isolated organisms, and determining the effectiveness of the cleaning solution or disinfectant being used on these inanimate objects for infection control. Thus, all these warrant indepth assessments.

\section{Declarations}

\section{Acknowledgments}

We would like to thank Ndola Teaching Hospital laboratory management and microbiology laboratory members of staff for allowing us to conduct this study as part of their infection control assessment and for providing the necessary materials for the study. We would like to thank Mr. Mike M. Nguluta and Mr. Edward Lungu for their unwavering assistance during the study process.

\section{Declaration of interest statement}

The authors declare no conflict of interest

\section{References}

1. HIV.gov. Opportunistic infections: HHS Secretary's Minority AIDS Initiative Fund; 2017 [updated 15 May 2017; cited 201822 May 2018]. Available from: www.hiv.gov/hiv-basics/staying-in-hiv-care/otherrelated-health-issues/opportunistic-infections. 
2. Kramer A, Schwebke I, Kampf G. How long do nosocomial pathogens persist on inanimate surfaces? A systematic review. BMC infectious diseases [Internet]. 2006 2006; 6:[130 p.]. Available from: http://europepmc.org/abstract/MED/16914034

http://europepmc.org/articles/PMC1564025?pdf=render

http://europepmc.org/articles/PMC1564025

https://doi.org/10.1186/1471-2334-6-130.

3. Galvin S, Dolan A, Cahill O, Daniels S, Humphreys H. Microbial monitoring of the hospital environment: why and how? J Hosp Infect. 2012;82(3):143-51.

4. Weinstein RA. Nosocomial Infection Update. Emerging Infectious Diseases 1998;4(3):416-20.

5. Huang SS, Datta R, Platt R. Risk of acquiring antibiotic-resistant bacteria from prior room occupants. Archives of Internal Medicine. 2006;166(18):1945-51.

6. Nseir S, Blazejewski C, Lubret R, Wallet F, Courcol R, Durocher A. Risk of acquiring multidrugresistant Gram-negative bacilli from prior room occupants in the intensive care unit. Clinical Microbiology and Infection. 2011;17(8):1201-8.

7. Rohr U, Kaminski A, Wilhelm M, Jurzik L, Gatermann S, Muhr G. Colonization of patients and contamination of the patients' environment by MRSA under conditions of single-room isolation. International Journal of Hygiene and Environmental Health. 2009;212(2):209-15.

8. Haley RW, Culver DH, White J, Morgan WM, Amber TG, Mann VP ea. The efficacy of infection surveillance and control programs in preventing nosocomial infections in US hospitals. . American Journal of Epidemiology. 1985;121:182-205.

9. Manian FA, Griesenauer S, Senkel D, Setzer JM, Doll SA, Perry AM, et al. Isolation of Acinetobacter baumannii Complex and Methicillin-Resistant Staphylococcus aureus from Hospital Rooms Following Terminal Cleaning and Disinfection: Can We Do Better? Infection Control \&\#x0026; Hospital Epidemiology. 2015;32(7):667-72.

10. CLSI. Performance Standards for antimicrobial Susceptibility Testing. 26 ed. Wayne PA: Clinical and Laboratory Standards Institute; 2016. 252 p.

11. Scott E, Bloomfield SF. The survival and transfer of microbial contamination via cloths, hands and utensils. The Journal of applied bacteriology. 1990;68(3):271-8.

12. Kandel CE, Simor AE, Redelmeier DA. Elevator buttons as unrecognized sources of bacterial colonization in hospitals. Open Med [Internet]. 2014 2014; 8(3):[e81-6 pp.]. Available from: http://europepmc.org/abstract/MED/25426176 
http://europepmc.org/articles/PMC4242253?pdf=render

http://europepmc.org/articles/PMC4242253.

13. Burke JP. Infection control - a problem for patient safety. The New England journal of medicine. 2003;348(7):651-6.

14. Best E, Parnell P, Couturier J, Barbut F, Le Bozec A, Arnoldo L, et al. Environmental contamination by bacteria in hospital washrooms according to hand-drying method: a multi-centre study. Journal of Hospital Infection. 2018;100(4):469-75.

15. Russotto V, Cortegiani A, Raineri SM, Giarratano A. Bacterial contamination of inanimate surfaces and equipment in the intensive care unit. J Intensive Care. 2015;3:54-.

16. Al-Ghamdi A, Abdelmalek S, Ashshi A, Faidah H, Shukri H, Jiman-Fatani A. Bacterial contamination of computer keyboards and mice, elevator buttons and shopping carts. African Journal of Microbiology Research. 2011;5(23):3998-4003.

17. Mohammadi A, Ebrahimi A, Nemati S. Bacterial and fungal contamination of elevator buttons in university schools of Isfahan University of Medical Sciences, Isfahan, Iran. Health Scope. 2016;5(4):e34428.

18. Kramer A, Assadian O. Survival of microorganisms on inanimate surfaces. Use of Biocidal Surfaces for Reduction of Healthcare Acquired Infections: Springer; 2014. p. 7-26.

19. Tang JW. The effect of environmental parameters on the survival of airborne infectious agents. Journal of the Royal Society Interface. 2009;6(suppl_6):S737-S46.

20. McDADE JJ, HALL LB. Survival of Staphylococcus aureus in the Environment. II. Effect of Elevated Temperature on Surface-Exposed Staphylococci. American journal of hygiene. 1964;80(2):184-91.

21. Chanda W, Manyepa M, Chikwanda E, Daka V, Chileshe J, Tembo M, et al. Evaluation of antibiotic susceptibility patterns of pathogens isolated from routine laboratory specimens at Ndola Teaching Hospital: A retrospective study. PloS one. 2019;14(12):e0226676-e.

22. Tong SY, Davis JS, Eichenberger E, Holland TL, Fowler VG. Staphylococcus aureus infections: epidemiology, pathophysiology, clinical manifestations, and management. Clinical microbiology reviews. 2015;28(3):603-61.

23. Becker K, Heilmann C, Peters G. Coagulase-negative staphylococci. Clinical microbiology reviews. 2014;27(4):870-926.

24. Gunnarsson G, Steinsson K. Sinusitis due to Stenotrophomonas maltophilia. Scandinavian journal of infectious diseases. 2002;34(2):136-7. 
25. Nawas T, Kassir R. Elevator buttons. 2018.

26. Yu W-L, Chuang Y-C. Clinical features, diagnosis, and treatment of Klebsiella pneumoniae infection. UpToDate. 2015.

27. Yusha'u M, Bello $M$, Sule H. Isolation of bacteria and fungi from personal and public mobile cellphones: A case study of Bayero University, Kano (Old Campus). Int J Biomed \& Hlth Sci. 2010;6:97102.

28. Amala S, Ejikema I. Bacteria Associated with the Mobile Phones of Medical Personnel. American Journal of Biomedical Sciences. 2015;7(1).

\section{Figures}
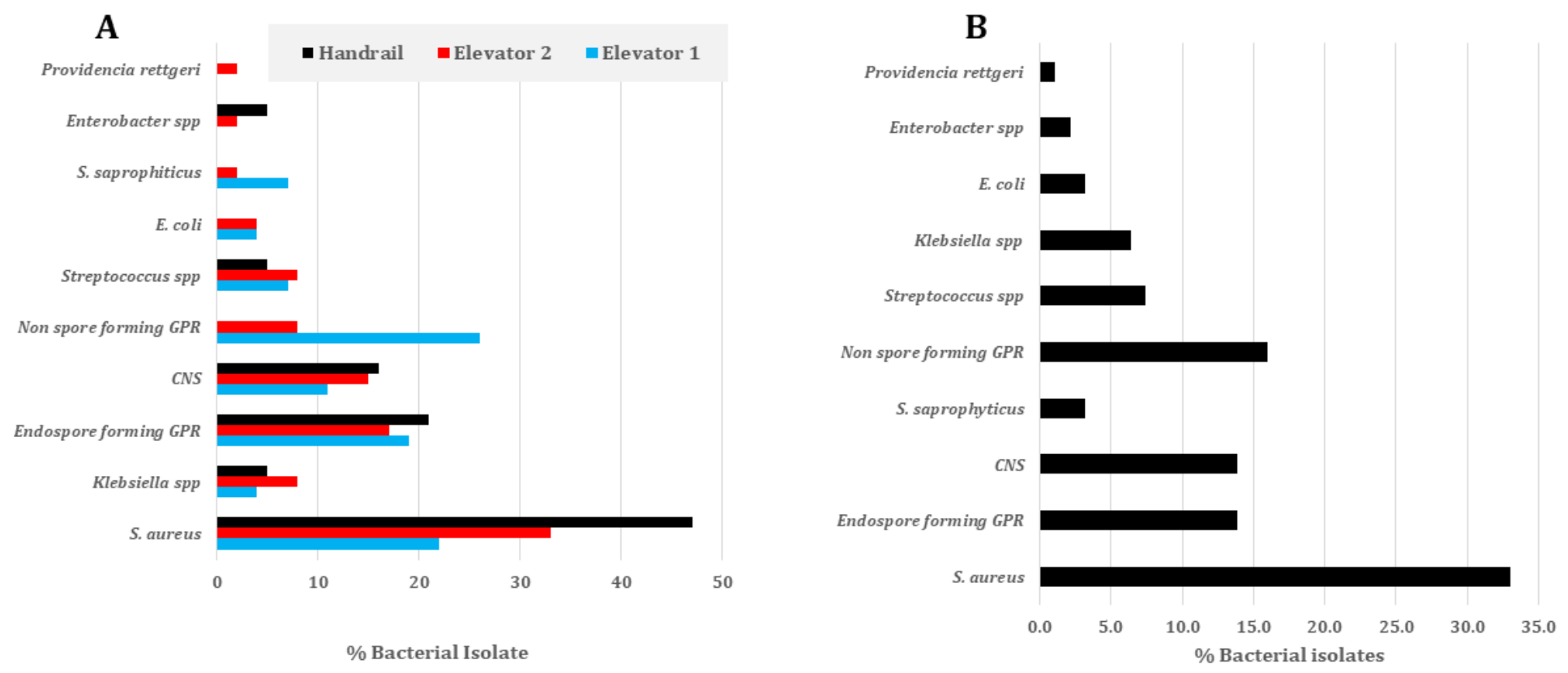

\section{Figure 1}

The percentage proportion (A) and prevalence (B) of bacterial isolates from elevators (1 and 2) and staircase handrail. CNS: coagulase negative Staphylococci, GPR: Gram positive rod, spp: species. 


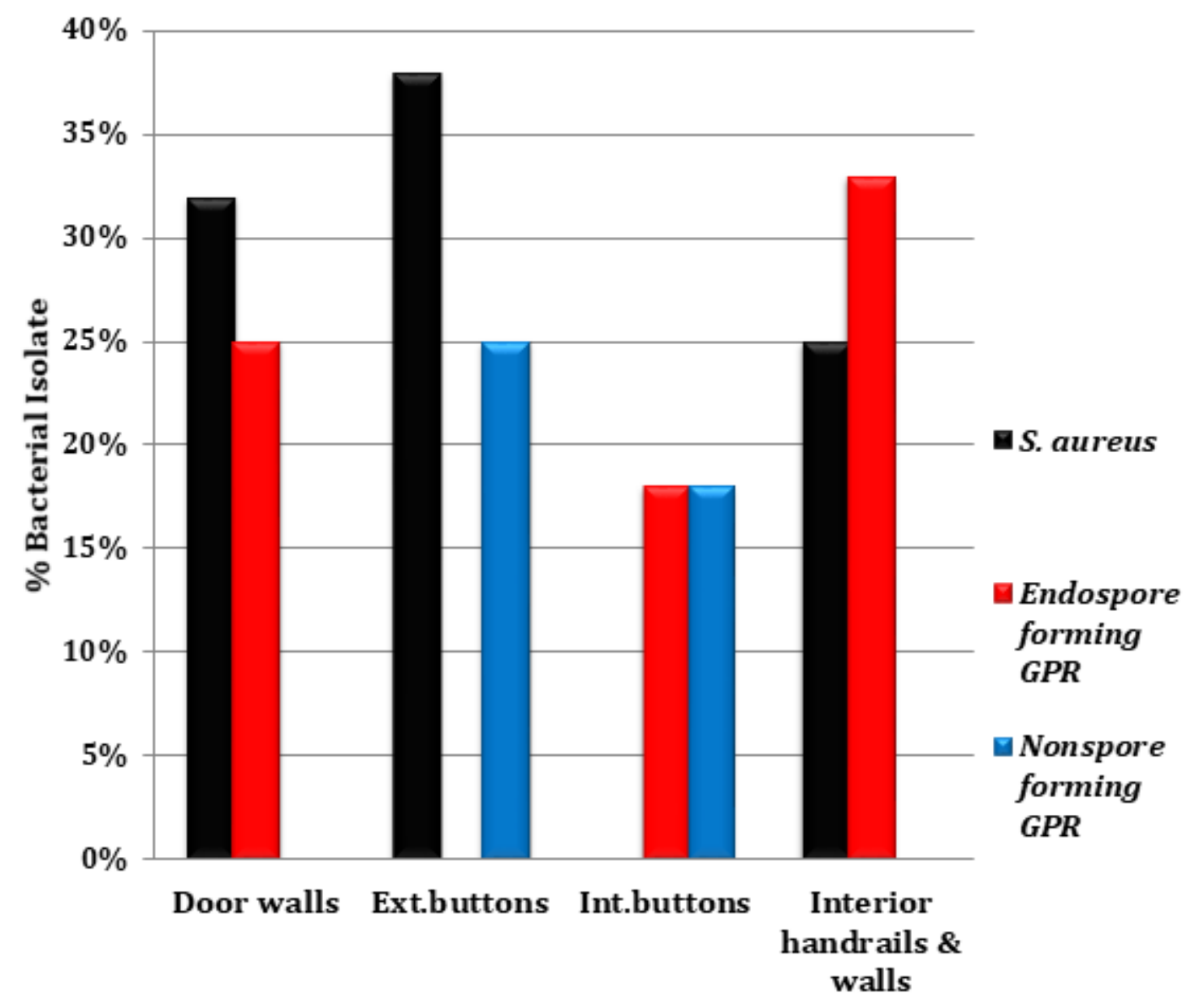

Swabbing site

Figure 2

The prevalence of most occurring bacteria isolates from both elevators (1 and 2) per swabbing site. GPR: Gram positive rods, Ext.buttons: exterior buttons, and Int.buttons: Interior buttons.

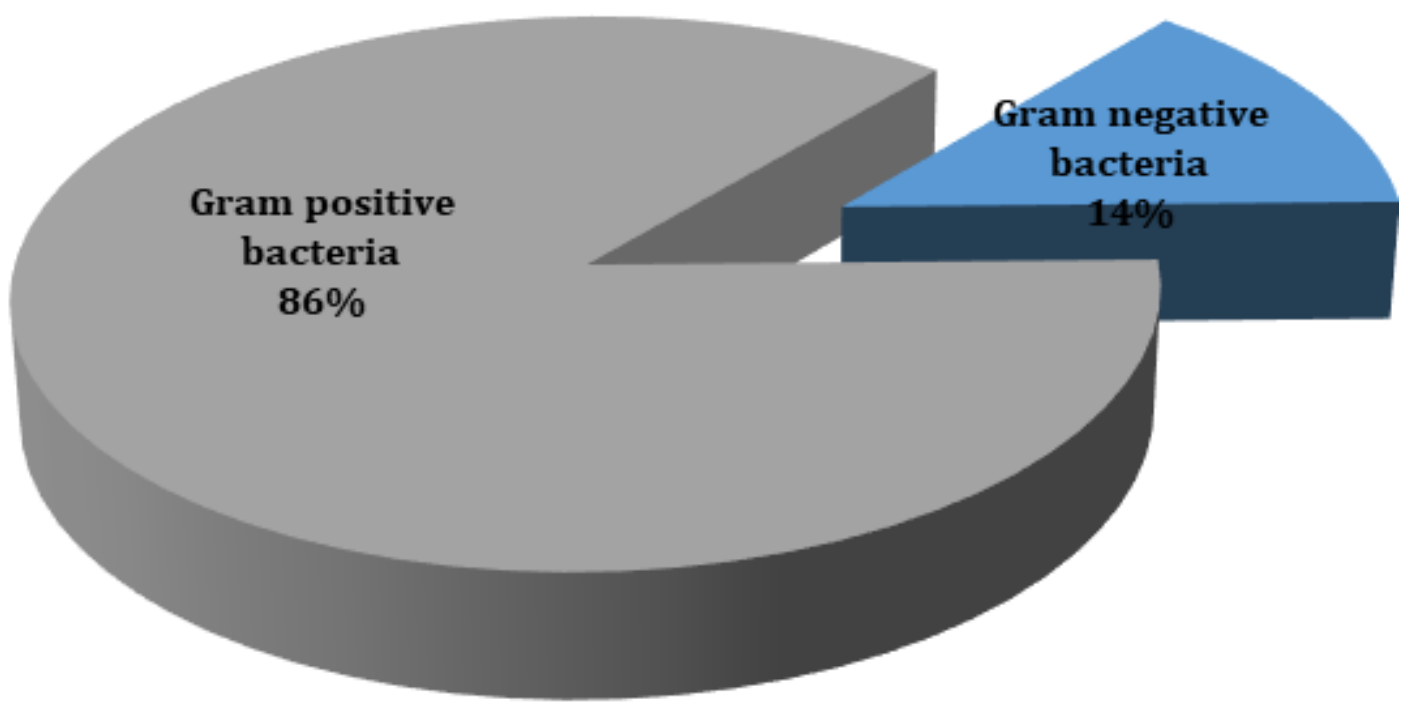

Figure 3 
The total distribution of Gram positive and Gram negative isolated bacteria from Staircase handrail and Elevators (1 and 2). 